\title{
Corrosion Behaviour of a Highly Alloyed Austenitic Alloy UB6 in Contaminated Phosphoric Acid
}

\author{
M. Boudalia, ${ }^{1}$ A. Guenbour, ${ }^{1}$ A. Bellaouchou, ${ }^{1}$ \\ R. M. Fernandez-Domene, ${ }^{2}$ and J. Garcia-Anton ${ }^{2}$ \\ ${ }^{1}$ Laboratoire de Corrosion-Electrochimie, Faculté des Sciences, Université Mohammed V-Agdal, Rabat BP 1014, Morocco \\ ${ }^{2}$ Ingeniería Electroquímica y Corrosión (IEC), Departamento de Ingeniería Química y Nuclear, ETSI Industriales, \\ Universitat Politècnica de Valencia, P.O. Box 22012, 46071 Valencia, Spain
}

Correspondence should be addressed to A. Guenbour; a_guenbour@yahoo.fr

Received 8 March 2013; Revised 9 June 2013; Accepted 15 June 2013

Academic Editor: W. Ke

Copyright (c) 2013 M. Boudalia et al. This is an open access article distributed under the Creative Commons Attribution License, which permits unrestricted use, distribution, and reproduction in any medium, provided the original work is properly cited.

\begin{abstract}
The influence of temperature $\left(20-80^{\circ} \mathrm{C}\right)$ on the electrochemical behaviour of passive films anodically formed on UB6 stainless steel in phosphoric acid solution $\left(5.5 \mathrm{M} \mathrm{H}_{3} \mathrm{PO}_{4}\right)$ has been examined by using potentiodynamic curves, electrochemical impedance spectroscopy, and Mott-Schottky analysis. UB6 stainless steel in contaminated phosphoric acid is characterised by high interfacial impedance, thereby, illustrating its high corrosion resistance. The obtained results show that the films behave as n-type and p-type semiconductors in the potential range above and below the flat band potential, respectively. This behaviour is assumed to be the consequence of the semiconducting properties of the iron oxide and chromium oxide regions which compose the passive film.
\end{abstract}

\section{Introduction}

In the phosphoric acid industry, the main stages of the wet process phosphoric acid (WPA) manufacture involve the attack of phosphate ore by concentrated sulphuric acid (98\%), filtration of the pulp, and concentration of acid [1]. Phosphoric acid in pure state is not very corrosive compared to nitric or sulphuric acids, but this process generates severe corrosion problems of the equipments made of stainless steels due to the presence of impurities such as chlorides, fluorides, and sulphides [1-4].

Depending on the nature of phosphates and the type of phosphoric acid manufacturing process used, the equipments (reactors, agitators, pumps, drain, etc.) are subjected to slower or faster deterioration [1].

The choice of materials used in this industrial process plays an important role since they must have both good chemical and mechanical resistance. These two characteristics are not always easy to obtain and a tradeoff between these properties must be reached [5]. In this sense, austenitic stainless steels are a good choice for phosphoric media. In this study, a highly alloyed austenitic stainless steel (UB6) has been used.

Stainless steels proved their good corrosion resistance in acid solutions. It was shown in the literature that chloride and fluorides ions accelerated the anodic process by altering passivity and activating the material dissolution rate [6-14].

UB6 stainless steel is used extensively in phosphoric acid industry, because of its good corrosion resistance; passive films formed on its surface have been the subject of some investigations [15].

The major disadvantage of these new alloys is their high cost compared with conventional stainless steels, due to the higher percentage of the alloying elements such as $\mathrm{Cr}, \mathrm{Ni}$, and Mo, as well as the complexity of the fabrication process [16].

The favourable effect of these alloying elements on the corrosion resistance is attributed to the formation of a protective passive surface film $[17,18]$. This film is stable, invisible, adherent, and self-repairing. In order to prevent corrosion, it is of paramount importance that stainless steels 
have a stable passive film with rapid passivation even in severe corrosive environments [17].

Several studies on the corrosion of various materials in phosphoric acid with addition of chemical ions $[19,20]$ and solid particles (abrasion effect) [21] have been carried out in our laboratory, as well as measurements in industrial phosphoric acid to study the behaviour in a real and complex medium [22].

The purpose of the present paper is to study the influence of the medium temperature $\left(20-80^{\circ} \mathrm{C}\right)$ on the corrosion behaviour of Alloy UB6 in a phosphoric acid solution by means of electrochemical techniques.

\section{Experimental Procedure}

The material used in this investigation has been stainless steel Uranus B6 (UB6); the chemical composition of this alloy is listed in Table 1. For all measurements, electrodes were mechanically polished using successively thinner grade of emery papers (400-4000 grades), then washed with distilled water, and dried with blowing warm air. Electrodes were circular shaped and the area of the samples exposed to the solution was $0.60 \mathrm{~cm}^{2}$. Platinum and $\mathrm{Ag} / \mathrm{AgCl} 3 \mathrm{M} \mathrm{KCl}$ electrodes were used as counter and reference electrodes, respectively. The electrolyte used in this study has been $(5.5 \mathrm{M}) \mathrm{H}_{3} \mathrm{PO}_{4}$ contaminated with addition of $4 \%$ of $\mathrm{H}_{2} \mathrm{SO}_{4}$ and $400 \mathrm{ppm}$ of chloride ions $(\mathrm{KCl})$. In this case, the solution has been called contaminated $\mathrm{H}_{3} \mathrm{PO}_{4}$ solution $(\mathrm{pH}=0.42)$.

The experiments were conducted under thermostated conditions at $20^{\circ} \mathrm{C}, 40^{\circ} \mathrm{C}, 60^{\circ} \mathrm{C}$, and $80^{\circ} \mathrm{C}$ in order to study the influence of temperature on the electrochemical behaviour and semiconducting properties of UB6 stainless steel.

Electrochemical measurements were performed by using an Autolab PGSTAT302N potentiostat. Potentiodynamic polarisation tests began at $-0.6 \mathrm{~V}_{\mathrm{Ag} / \mathrm{AgCl}}$ and the potential was subsequently scanned anodically at a scan rate of $0.5 \mathrm{~m} \mathrm{Vs}^{-1}$.

Before the potentiostatic passivation experiments, the surface of the samples was pretreated cathodically at $-0.6 \mathrm{~V}_{\mathrm{Ag} / \mathrm{AgCl}}$ for 15 minutes to create reproducible initial conditions. Afterwards, the working electrode was polarised at a formation potential of $0.6 \mathrm{~V}_{\mathrm{Ag} / \mathrm{AgCl}}$ (within the passive range) for 1 hour at different temperatures to form a steadystate passive film.

EIS and capacitance measurements were performed after potentiostatic passivation tests, once a stable passive film was formed on the samples surface. EIS measurements were conducted at the formation potential $\left(0.6 \mathrm{~V}_{\mathrm{Ag} / \mathrm{AgCl}}\right)$ in the frequency range of $100 \mathrm{kHz}-10 \mathrm{mHz}$, with an amplitude signal of $10 \mathrm{mV}$. Subsequently, the capacitance of the interface was calculated at a constant frequency of $5 \mathrm{kHz}$ using a $10 \mathrm{mV}$ amplitude signal and scanning the potential from the formation value in the negative direction at a rate of $25 \mathrm{mV} \mathrm{s}^{-1}$. The high scanning rate was used to avoid the electroreduction of the passive film and the change in the film thickness during the measurements. Moreover, at a sufficiently high scanning rate, the defect structure within the passive film is, "frozen-in" which avoids the defect density from being affected by potential.

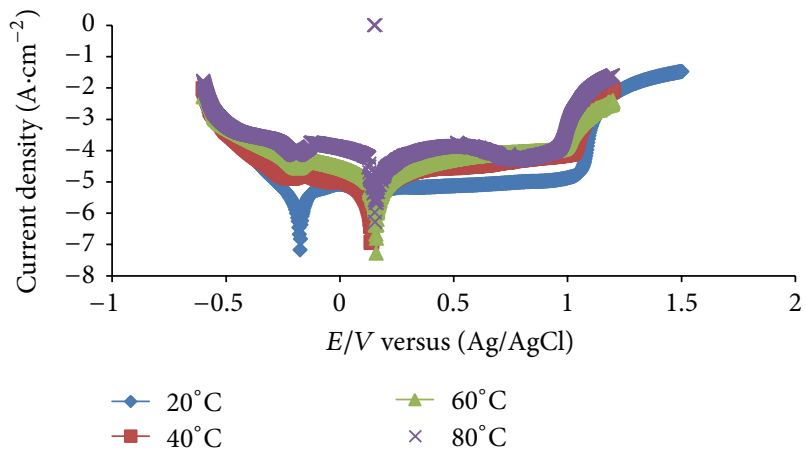

Figure 1: Potentiodynamic curves obtained on stainless steel in contaminated $5.5 \mathrm{M}$ phosphoric acid at the temperatures of $20^{\circ} \mathrm{C}$, $40^{\circ} \mathrm{C}, 60^{\circ} \mathrm{C}$, and $80^{\circ} \mathrm{C}$.

\section{Results and Discussion}

3.1. Potentiodynamic Response. Polarisation curves of Alloy UB6 recorded in the contaminated phosphoric acid solution at different temperatures are illustrated in Figure 1.

Figure 1 shows that Alloy UB6 has a good passive behaviour with a large passive domain. This behaviour may be attributed to the chemical composition of the alloy rich on $\mathrm{Cr}, \mathrm{Ni}$, and Mo. At anodic potentials, the formation of $\mathrm{Fe}, \mathrm{Cr}$, and $\mathrm{Ni}$ oxides expected the following the reactions [4]:

$$
\begin{aligned}
& \mathrm{Fe}+\mathrm{H}_{2} \mathrm{O} \longrightarrow \mathrm{FeO}+2 \mathrm{H}^{+}+2 \mathrm{e}^{-} \\
& \mathrm{Ni}+\mathrm{H}_{2} \mathrm{O} \longrightarrow \mathrm{NiO}+2 \mathrm{H}^{+}+2 \mathrm{e}^{-} \\
& \mathrm{Cr}+\mathrm{H}_{2} \mathrm{O} \longrightarrow \mathrm{CrO}+2 \mathrm{H}^{+}+2 \mathrm{e}^{-}
\end{aligned}
$$

The formation of iron oxide took place through a dissolution-precipitation mechanism, in which the formed compound was soluble and started to deposit on the electrode surface, whereas the formation of both chromium and nickel oxides took place by direct nucleation and growth mechanism on the electrode surface. Then, the formation of higher oxidized forms of iron and chromium was expected as well as some thickening of nickel oxide,

$$
\begin{aligned}
& 2 \mathrm{FeO}+\mathrm{H}_{2} \mathrm{O} \longrightarrow \mathrm{Fe}_{2} \mathrm{O}_{3}+2 \mathrm{H}^{+}+2 \mathrm{e}^{-} \\
& 2 \mathrm{CrO}+\mathrm{H}_{2} \mathrm{O} \longrightarrow \mathrm{Cr}_{2} \mathrm{O}_{3}+2 \mathrm{H}^{+}+2 \mathrm{e}
\end{aligned}
$$

Some authors considered that chromium oxide $\left(\mathrm{Cr}_{2} \mathrm{O}_{3}\right)$ is the main component of the passive film formed on stainless steels $[23,24]$. Nickel is able to reduce the corrosion rate and passive current density, and molybdenum addition in stainless steels is known to increase the resistance to pitting corrosion [25]. Besides, the role of $\mathrm{Ni}$ and $\mathrm{Mo}$ in stainless steel at anodic potentials in phosphoric acid solution is to stabilise the passive film and to eliminate the active surface sites. In highly concentrated $\mathrm{H}_{3} \mathrm{PO}_{4}$ electrolytes, precipitation of iron phosphate can occur at the interface $[26,27]$, according to

$$
\begin{aligned}
& 6 \mathrm{H}_{3} \mathrm{PO}_{4}+3 \mathrm{Fe} \longrightarrow 3 \mathrm{Fe}\left(\mathrm{H}_{2} \mathrm{PO}_{4}\right)_{2}+3 \mathrm{H}_{2} \\
& 3 \mathrm{Fe}\left(\mathrm{H}_{2} \mathrm{PO}_{4}\right)_{2} \longrightarrow \mathrm{Fe}_{3}\left(\mathrm{PO}_{4}\right)_{2}+4 \mathrm{H}_{3} \mathrm{PO}_{4}
\end{aligned}
$$


TABLE 1: Chemical composition of Alloy UB6.

\begin{tabular}{lcccccccccc}
\hline \multirow{2}{*}{ Alloy } & & \multicolumn{9}{c}{ Chemical composition (wt\%) } \\
& $\mathrm{Ni}$ & $\mathrm{Cr}$ & $\mathrm{Fe}$ & $\mathrm{Mo}$ & $\mathrm{C}$ & $\mathrm{Mn}$ & $\mathrm{Si}$ & $\mathrm{S}$ & $\mathrm{P}$ & Others \\
\hline UB6 & 25.09 & 20.77 & 43.97 & 4.39 & 0.0013 & 1.84 & 1.45 & 0.007 & 0.0029 & $2.36 \mathrm{CU}$ \\
\hline
\end{tabular}

TABLE 2: Electrical parameters obtained by polarization curves for the alloy in the UB6 $\mathrm{H}_{3} \mathrm{PO}_{4}$ polluted solution at different temperatures.

\begin{tabular}{lcccc}
\hline & $20^{\circ} \mathrm{C}$ & $40^{\circ} \mathrm{C}$ & $60^{\circ} \mathrm{C}$ & $80^{\circ} \mathrm{C}$ \\
\hline$i_{\text {corr }}\left(\mu \mathrm{A} \cdot \mathrm{cm}^{-2}\right)$ & 40.9 & 57.3 & 74.6 & 80.4 \\
$E_{\text {corr }}\left(\mathrm{mV} /_{\mathrm{Ag} / \mathrm{AgCl}}\right)$ & -172.3 & 136.8 & 154.8 & 157.1 \\
$i_{p}\left(\mu \mathrm{A} \cdot \mathrm{cm}^{-2}\right)$ & 37.1 & 44.3 & 46.3 & 57 \\
$E_{\mathrm{cr}}\left(\mathrm{mV} /_{\mathrm{AgCl} / \mathrm{Ag}}\right)$ & -10.6 & 453 & 603 & 614 \\
\hline
\end{tabular}

The electrochemical parameters obtained from polarisation curves are shown in Table 2 . It can be seen that the increase of temperature leads to the increase in the passive current density $\left(i_{p}\right)$, an ennoblement of corrosion potential and a decrease of the domain of passivity $\left(E_{\mathrm{cr}}-\right.$ $\left.E_{\text {corr }}\right)[5,28]$. It is observed from the data obtained that the increase in temperature from 20 to $80^{\circ} \mathrm{C}$ induces a shift in the corrosion potential $\left(E_{\text {corr }}\right)$ towards more anodic values, from -172.3 to $157.1 \mathrm{mV}$, respectively. An increase in corrosion current density values from 40.9 to $80.4 \mu \mathrm{A} \cdot \mathrm{cm}^{-2}$ can also be observed as temperature increases from 20 to $80^{\circ} \mathrm{C}$.

In spite of the temperature increase, Alloy UB6 preserves a stable passivity in the range of potentials studied. The sharp increase in current density at a high potential $\left(E_{\mathrm{cr}}\right)$ indicates the onset of transpassive dissolution of the $\mathrm{Cr}$-species present in the passive film formed on Alloy UB6.

Polarisation curves have been used to set the value of the film formation potential within the passive range of UB6. A film formation potential of $0.6 \mathrm{~V}_{\mathrm{Ag} / \mathrm{AgCl}}$ has been selected.

3.2. EIS Measurements. Electrochemical impedance spectroscopy (EIS) has been employed to investigate the steadystate properties of the passive films formed on Alloy UB6. Once the passive film was formed on the electrode surface, the EIS measurements were conducted at the formation potential $\left(0.6 \mathrm{~V}_{\mathrm{Ag} / \mathrm{AgCl}}\right)$ at different temperatures $\left(20^{\circ} \mathrm{C}, 40^{\circ} \mathrm{C}\right.$, $60^{\circ} \mathrm{C}$, and $80^{\circ} \mathrm{C}$ ).

Figure 2 shows the Nyquist plots for UB6 stainless steel in the contaminated $5.5 \mathrm{M} \mathrm{H}_{3} \mathrm{PO}_{4}$ solution. These complex plane plots have all the same semicircular shape which may correspond to a large diameter charge-transfer dominated region with some diffusion control, as found in other corrosion systems [29]. This form of impedance is consistent with the occurrence of a charge transfer reaction in a porous film of finite thickness [30], although oxygen evolution occurring within a thick porous outer layer may exhibit such behaviour [31]. It can be observed that an increase in temperature reduces the amplitude of the semicircle, indicating a decrease of the total impedance of the system and a loss in the protective properties of the passive film. This evolution with

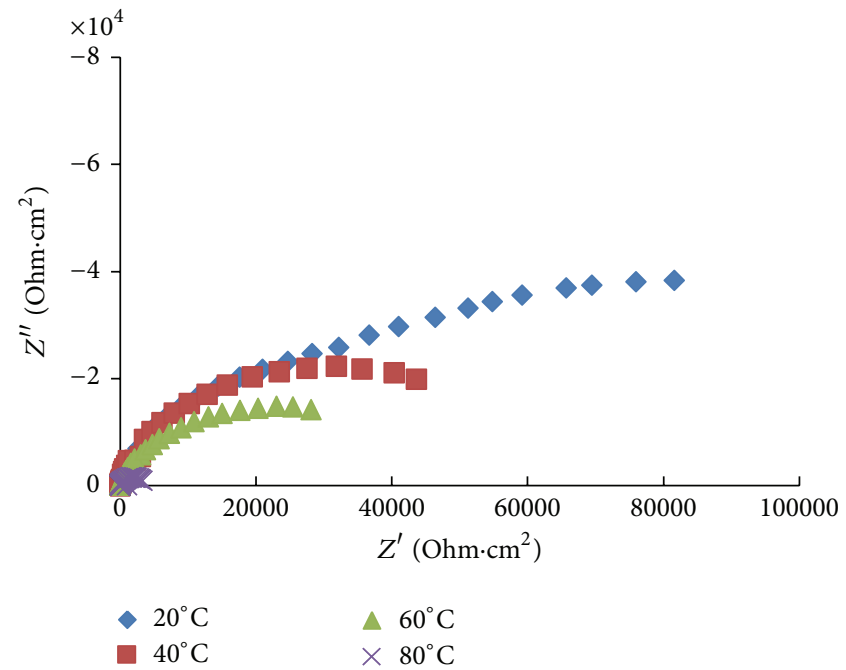

FIgURE 2: Nyquist plots for the UB6 in contaminated $5.5 \mathrm{M}$ phosphoric acid at $+0.6 \mathrm{~V}_{\mathrm{Ag} / \mathrm{AgCl}}$ at the temperatures of $20^{\circ} \mathrm{C}, 40^{\circ} \mathrm{C}, 60^{\circ} \mathrm{C}$, and $80^{\circ} \mathrm{C}$.

temperature suggests an evolution of the charge exchange between the material and the solution occurring at the surface [32].

The functionality with respect to frequency is seen more clearly in the Bode-phase representation shown in Figure 3. The phase angle plots are sensitive to system parameters and, therefore, provide a good means of comparing the model to the experiment. It can be seen from these plots that an increase in temperature decreases the phase angle values at low frequencies, indicating worse protective properties of the passive film formed on the UB6 surface.

3.3. Equivalent Circuit and Interpretation. The superior corrosion resistance of austenitic stainless steels, such as Alloy UB6, is closely related to the passive film formed on their surface [33-39]. The compact inner layer, known as barrier layer, is composed principally of chromium oxides and is the major contribution. The porous outer layer is composed principally of iron oxides and hydroxides.

Figure 4 shows the equivalent circuit (EC) that has been usually used to interpret EIS spectra of passive films having a two-layer structure [37, 40-42]. This circuit has two hierarchically distributed time constants and it has been used to simulate the electrochemical behaviour of the present system Alloy UB6/contaminated $5.5 \mathrm{M} \mathrm{H}_{3} \mathrm{PO}_{4}$ solution. In this model, $R_{1}, \mathrm{CPE}_{1}, R_{2}$, and $\mathrm{CPE}_{2}$ correspond to the resistance and capacitance of the outer porous layer and inner layer, respectively. In this sense, the passive film consists of two layers: the inner barrier layer and the outer layer. 


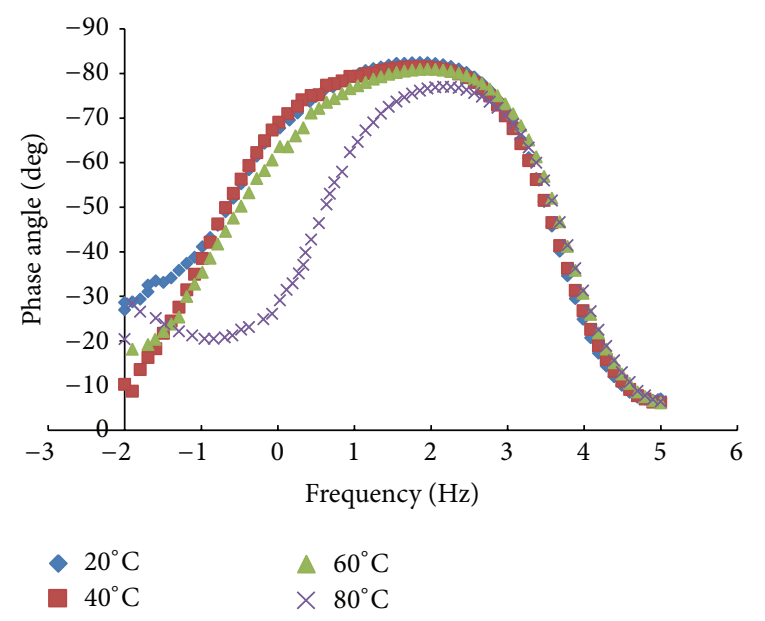

FIgURE 3: Bode-phase plots for the UB6 in contaminated $5.5 \mathrm{M}$ phosphoric acid at $+0.6 \mathrm{~V}_{\mathrm{Ag} / \mathrm{AgCl}}$ at the temperatures of $20^{\circ} \mathrm{C}, 40^{\circ} \mathrm{C}$, $60^{\circ} \mathrm{C}$, and $80^{\circ} \mathrm{C}$.

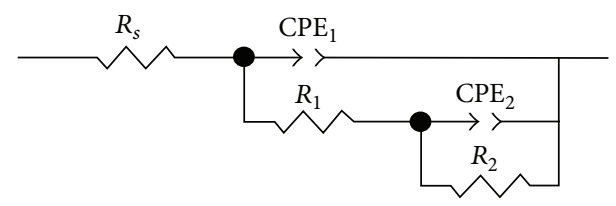

FIGURE 4: Representation of the equivalent circuits used for twolayer model of passive film and proposed for the interpretation of EIS spectra.

A constant-phase element (CPE) representing a shift from ideal capacitor was used instead of the capacitance itself. CPEs are used to model frequency dispersion behaviour corresponding to different physical phenomena such as surface heterogeneity which results from surface roughness, impurities, dislocations, and formation of porous layers [36, $41,43,44]$. The impedance of a constant-phase element is defined as

$$
Q=Z_{\mathrm{CPE}}=\left[C(j \omega)^{\alpha}\right]^{-1}
$$

where $\alpha$ is defined as a CPE power, in an adjustable parameter that lies between -1 and 1 . For $\alpha=1$, the CPE describes an ideal capacitor, and for $\alpha=0$, the CPE is an ideal resistor. When $\alpha=0.5$, the CPE represents a Warburg impedance with diffusional character, and for $0.5<\alpha<1$, the CPE describes a frequency dispersion of time constants due to local heterogeneities in the dielectric material. A pure inductance yields $\alpha=-1$.

The CPE elements, $Q$, have been converted into a pure capacitance $(C)$ by means of the following equation [45-47]:

$$
C=\frac{(Q \cdot R)^{1 / \alpha}}{R}
$$

where $Q=Z_{\mathrm{CPE}}($ see $(8))$.
The conversion shown in (8) has been done in order to relate pure capacitance values $(C)$ to the thickness of passive film layers, according to the following equation $[48,49]$ :

$$
C=\frac{\varepsilon \cdot \varepsilon_{0}}{d},
$$

where $\varepsilon$ denotes the relative dielectric constant of the layer, $\varepsilon_{0}$ is the permittivity of vacuum $\left(8.85 * 10^{-14} \mathrm{Fcm}^{-1}\right)$, and $d$ is the layer thickness. A value of 15.6 has been assumed for $\varepsilon$, as in the literature for austenitic stainless steels $[27,50]$. This value is reasonable, since the dielectric constants of the bulk oxides formed on stainless steels $\left(\mathrm{Cr}_{2} \mathrm{O}_{3}, \mathrm{FeO}, \mathrm{Fe}_{3} \mathrm{O}_{4}\right.$, and $\left.\mathrm{Fe}_{2} \mathrm{O}_{3}\right)$ are about 10-20 [50,51]. It is complicated to obtain an accurate thickness value of the passive film when the dielectric constant is not well established and when the surface roughness varies substantially during the oxidation process [41, 47, 48, 52]. Moreover, because of the open porous structure, it is difficult to calculate the thickness of the outer layer from the $C_{1}$ values [37]. Nevertheless, neglecting some variations in the surface roughness and the dielectric constant, the capacitive response under different conditions can give an indication of how the passive film thickness changes with the changing system conditions.

Parameters obtained by adjusting the experimental data, as well as the thickness of both porous and barrier layers obtained from (9), are given in Table 3. It can be seen that $R_{1}$ and $R_{2}$ values are far higher than $R_{S}$ values for all tests. Thus, $R_{1}$ and $R_{2}$ can be related to the passive film. Moreover, the resistance of the inner oxide layer $\left(R_{2}\right)$ is larger than the values associated with the outer porous layer $\left(R_{1}\right)$, which is consistent with the chosen physical model. It can be said that $R_{1}$ is associated with the resistance of charge transfer processes in the defects of the outer layer of the passive film, while $R_{2}$ is assigned to the areas covered with the protective inner layer of the passive film (barrier layer) [53]. These results indicate that the protection provided by the passive film was predominantly due to the barrier layer. Similar results were obtained by other authors [36, 54-56].

$R_{1}$ slightly decreases as temperature increases, which suggests that temperature favours the formation of a more porous film and this behaviour could be related to the fact that at lower temperatures the outer porous layer is more stable. On the other hand, the parameter $R_{2}$ associated with the inner oxide film is more sharply affected by temperature. $R_{2}$ clearly decreases when temperature increases, which suggests a loss of the protective properties of the inner layer of the passive film.

Concerning the capacitance values, it can be observed that $C_{1}<C_{2}$, which suggests that the outer layer of the passive film is thicker than the inner layer, although its resistance is lower. These results evidence that the passive film thickness is not directly related to its protective properties.

The high values of the exponent $\alpha_{1}$ reveal that CPEs correspond to a nearly capacitive response and support the physical validity of the proposed equivalent circuit, showing that a better agreement between theoretical and experimental data is obtained. The exponent has values close to 0.9 , which indicates that the interpretation of the $\mathrm{CPE}_{1}$ element as a capacitance should be acceptable, whereas the values of $\alpha_{2}$ 
TABLE 3: Parameters obtained by fitting the experimental results of EIS for the alloy in contaminated $5.5 \mathrm{M} \mathrm{H}_{3} \mathrm{PO}_{4}$ solution at $+0.6 \mathrm{mV}$ at different temperatures.

\begin{tabular}{|c|c|c|c|c|c|c|c|c|c|c|}
\hline Temperature & $\begin{array}{c}R_{S} \\
\left(\mathrm{Ohm} \cdot \mathrm{cm}^{2}\right) \\
\end{array}$ & $\begin{array}{c}R_{1} \\
\left(\mathrm{Ohm} \cdot \mathrm{cm}^{2}\right) \\
\end{array}$ & $\begin{array}{c}C_{1} \\
\left(\mu \mathrm{F} \cdot \mathrm{cm}^{-2}\right)\end{array}$ & $\alpha_{1}$ & $\begin{array}{c}d_{1} \\
(\mathrm{~nm})\end{array}$ & $\begin{array}{c}R_{2} \\
\left(\mathrm{Ohm} \cdot \mathrm{cm}^{2}\right)\end{array}$ & $\begin{array}{c}C_{2} \\
\left(\mu \mathrm{F} \cdot \mathrm{cm}^{-2}\right)\end{array}$ & $\alpha_{2}$ & $\begin{array}{c}d_{2} \\
(\mathrm{~nm})\end{array}$ & $\begin{array}{c}d_{T} \\
(\mathrm{~nm}) \\
\end{array}$ \\
\hline $20^{\circ} \mathrm{C}$ & 4.16 & 204 & 13.7 & 0.95 & 1 & 644 & 38.2 & 0.7 & 0.36 & 1.36 \\
\hline $40^{\circ} \mathrm{C}$ & 3.79 & 185 & 15.7 & 0.94 & 0.87 & 569 & 39.3 & 0.66 & 0.35 & 1.22 \\
\hline $60^{\circ} \mathrm{C}$ & 3.41 & 169 & 17.0 & 0.9 & 0.81 & 340 & 42.6 & 0.6 & 0.32 & 1.13 \\
\hline $80^{\circ} \mathrm{C}$ & 2.42 & 159 & 17.5 & 0.94 & 0.7 & 234 & 70.1 & 0.52 & 0.19 & 0.88 \\
\hline
\end{tabular}

were between 0.5 and 0.8 . The values of $\alpha_{1}$ and $\alpha_{2}$ decrease as temperature increases, indicating that the electrode surface becomes more rough and heterogeneous with temperature.

The estimated values of $d_{T}=d_{1}+d_{2}$ calculated with (9) show that the layers formed on Alloy UB6 are typically on the order of $\mathrm{nm}$ in thickness, within the typical range for passive films formed on stainless steel (1-3 nm) [57].

3.4. M-S Analysis. The Mott-Schottky (M-S) analysis has been employed to determine the electronic properties of the passive films formed on UB6 stainless steel in the contaminated $5.5 \mathrm{M} \mathrm{H}_{3} \mathrm{PO}_{4}$ solution.

The Mott-Schottky approach assumes that the capacitance response is controlled by the band bending and can be described by the variation of the space charge capacitance under depletion conditions. When the passive or oxide films are in contact with an electrolyte, the space charge region developed in the passive film and the Helmholtz layer can be considered as two capacitors in series. Thus, the measured capacitance of the film-electrolyte interface can be described by the following relation $[58,59]$ :

$$
\frac{1}{C}=\frac{1}{C_{\mathrm{SC}}}+\frac{1}{C_{H}},
$$

where $C_{S C}$ and $C_{H}$ are the space charge layer capacitance and the Helmholtz layer capacitance, respectively. Presented as the Mott-Schottky relation, the expression becomes

$$
\frac{1}{C^{2}}=\frac{1}{C_{\mathrm{SC}}^{2}}+\frac{1}{C_{H}^{2}}+\frac{2}{C_{\mathrm{SC}} C_{H}}
$$

In the case of the classical semiconductors (type: $\mathrm{Si}, \mathrm{Ge}$, ...) characterized by a doping density around $10^{16} \mathrm{~cm}^{-3}$, the space charge capacitance is very small compared to that of the Helmholtz layer. In these conditions, the contribution of the second and third terms can be neglected. When the heavily doped $\left(10^{19}-10^{20} \mathrm{~cm}^{-3}\right)$ passive films are considered, the capacitance of the space charge region becomes important (but is still smaller than that of the Helmholtz layer). In this case, the passive film-electrolyte interface can be described by the following Mott-Schottky relation [60]:

$$
\begin{aligned}
& \frac{1}{C^{2}}=\frac{1}{C_{H}^{2}}=\frac{2}{\varepsilon \varepsilon_{0} e N_{D}}\left(E-E_{\mathrm{FB}}-\frac{k T}{e}\right) \quad \text { n-type, } \\
& \frac{1}{C^{2}}=\frac{1}{C_{H}^{2}}-\frac{2}{\varepsilon \varepsilon_{0} e N_{A}}\left(E-E_{\mathrm{FB}}-\frac{k T}{e}\right) \quad \text { p-type, }
\end{aligned}
$$

where $N_{D} / N_{A}$ are the donor/acceptor density in the passive film, $\varepsilon$ is the dielectric constant of the oxide, $\varepsilon_{0}$ is the vacuum permittivity constant, $e$ is the electron charge $\left(1.602 \times 10^{-19} \mathrm{C}\right), k$ is the Boltzmann constant $\left(1.38 \times 10^{-23}\right.$ $\left.\mathrm{J} \cdot \mathrm{K}^{-1}\right), T$ is the absolute temperature, and $E_{\mathrm{fb}}$ is the flatband potential. For a p-type semiconductor, $1 / C^{2}$ versus $E$ should be linear with a negative slope that is inversely proportional to the acceptor density. On the other hand, an ntype semiconductor yields a positive slope which is inversely proportional to the donor density.

Figure 5 presents Mott-Schottky curves for the passive films formed in the contaminated phosphoric acid solution at $20^{\circ} \mathrm{C}, 40^{\circ} \mathrm{C}, 60^{\circ} \mathrm{C}$, and $80^{\circ} \mathrm{C}$ at the formation potential of $0.6 \mathrm{~V}_{\mathrm{Ag} / \mathrm{AgCl}}$. These curves exhibit two linear regions, above and below the flat band potential, $E_{\mathrm{FB}}$, which is located between 0 and $0.1 \mathrm{~V}_{\mathrm{Ag} / \mathrm{AgCl}}$. Inside the potential region above $E_{\mathrm{FB}}$, the measured capacitance corresponds to the outer layer of the film, which is composed mainly of iron (III) oxide, and there is also the effect of phosphates [26] as well as the presence of other compounds $[58,61,62]$. The positive slope of this linear region clearly shows that the outer layer of the passive film formed on UB6 is an n-type semiconductor. On the contrary, inside the potential region below $E_{\mathrm{FB}}$, the slope of the straight line is negative, so the capacitance measured corresponds to a p-type semiconductor that may be attributed to an inner $\mathrm{Cr}$ enriched oxide layer of the passive film formed on the alloy surface [26, 63-65]. These results have also been observed in other works $[66,67]$.

According to Mott-Schottky theory [68], the capacitance of the film/electrolyte interface for $\mathrm{p}$ - and n-type semiconductors is given by (13) and (14). Donor density, $N_{D}$, and acceptor density, $N_{A}$, can be determined from the slope of the experimental $C^{-2}$ versus $E$ plots.

Table 4 summarises the values of $N_{D}$ and $N_{A}$ corresponding to Alloy UB6. The density of defects is in the range between $10^{20}$ and $10^{21} \mathrm{~cm}^{-3}$, which are of the same order of magnitude as those reported for austenitic stainless steels in several papers $[35,69-72]$. These defects act as dopants, that is, oxygen vacancies and cation interstitials imparting $n$-type properties and cation vacancies yielding p-type character $[70,71]$.

Based on the values of Table 4, it can be concluded that the passive film formed on UB6 steel is disordered, which becomes more visible at higher temperatures. The decrease in the slope when the temperature increases indicates that the concentration of donor and acceptor species in the passive film increases with temperature [69]. Higher donor and 
TABLE 4: Donor and acceptor density of the oxide films formed on UB6 stainless steel at different temperatures between 20 and $80^{\circ} \mathrm{C}$.

\begin{tabular}{lcccccc}
\hline Temperature & $N_{A}\left(10^{20} \cdot \mathrm{cm}^{-3}\right)$ & $N_{D}\left(10^{20} \cdot \mathrm{cm}^{-3}\right)$ & $C_{1 \mathrm{sc} \text { (outer) }}\left(\mu \mathrm{F} \cdot \mathrm{cm}^{-2}\right)$ & $C_{2 \text { sc (innerr) }}\left(\mu \mathrm{F} \cdot \mathrm{cm}^{-2}\right)$ & $d_{1(\text { outer })}(\mathrm{nm})$ & $d_{2(\text { innerr })}(\mathrm{nm})$ \\
\hline $20^{\circ} \mathrm{C}$ & 5.54 & 2.03 & 24.66 & 20.89 & 0.67 & 0.66 \\
$40^{\circ} \mathrm{C}$ & 9.33 & 3.95 & 20.61 & 29.55 & 0.66 & 0.46 \\
$60^{\circ} \mathrm{C}$ & 10.3 & 4.71 & 18.6 & 36.52 & 0.60 & 0.37 \\
$80^{\circ} \mathrm{C}$ & 24.3 & 5.60 & 17.0 & 75.21 & 0.57 & 0.18 \\
\hline
\end{tabular}

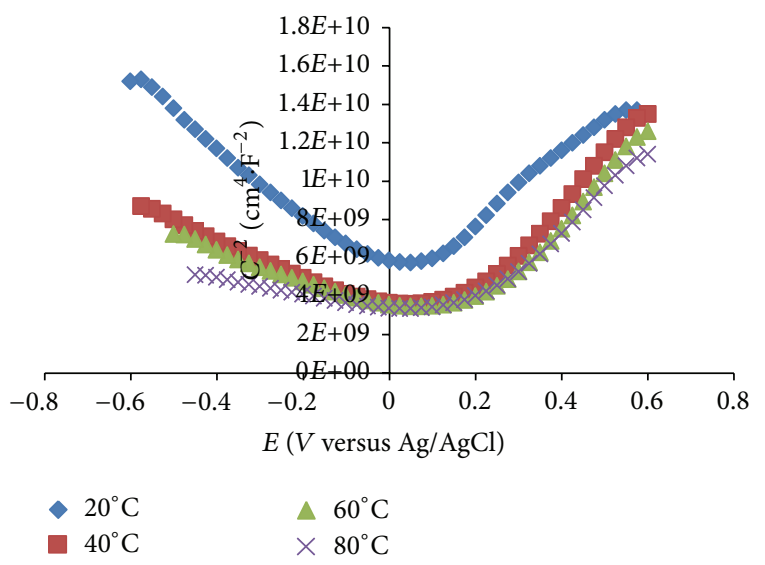

FIGURE 5: Mott-Schottky curves for the passive films formed in contaminated $5.5 \mathrm{M}$ phosphoric acid at $20^{\circ} \mathrm{C}, 40^{\circ} \mathrm{C}, 60^{\circ} \mathrm{C}$, and $80^{\circ} \mathrm{C}$ at the formation potential of $0.6 \mathrm{~V}_{\mathrm{Ag} / \mathrm{AgCl}}$.

acceptor density values at elevated temperatures means that the passive films formed on UB6 steel exhibit a more defective structure and worse protective properties, as observed in the EIS measurements.

According to the results obtained in the Mott-Schottky analysis, two space-charge regions appear at the metal/inner layer and outer layer/electrolyte interfaces. The capacitance of these two space-charge layers can be estimated from the capacitance values measured at those two-potentials, where $1 / \mathrm{C}^{2}$ reaches a maximum in the Mott-Schottky plots, that is, at the formation potential (thickness of the outer layer) and at the most negative potential (thickness of the inner layer). The contribution of the Helmholtz layer capacitance $\left(C_{H}\right)$ to the total capacitance has not been neglected, and its value has been taken as the capacitance at the flat-band potential, for each temperature. Arranging (11) is as follows:

$$
C_{\mathrm{SC}}=\frac{C \cdot C_{H}}{C_{H}-C} .
$$

Thereafter, the thickness of the outer and inner layers of the film can be calculated using (10). Values of $C_{S C}$ and thicknesses $(d)$ are presented in Table 4 .

It can be observed that the inner layer exhibits higher capacitance $\left(C_{2} s c\right)$ than the outer layer $\left(C_{1} s c\right)$, especially at high temperatures, which means that the inner layer is thinner than the outer layer. These findings agree with the previous results obtained by EIS, validating the equivalent circuit chosen to interpret the experimental results.

\section{Conclusions}

The electrochemical behaviour of the passive film formed on Alloy UB6 in contaminated phosphoric acid (5.5 M) was investigated using potentiodynamic polarisation, EIS, and M$\mathrm{S}$ analysis, and the following conclusions were drawn.

(1) The potentiodynamic polarisation curves were characterised by a very wide passive range indicating good protection efficiency. The passive current density increased and the transpassive potential decreased as temperature increased in the studied solution, indicating a decrease in corrosion resistance with temperature.

(2) The impedance has been found to be dependant on the temperature of the electrolyte, indicating the occurrence of a charge transfer reaction in a porous film. EIS measurements showed that the protection provided by the passive film was predominantly due to the inner oxide film. The resistance of the outer porous layer $R_{1}$ decreased slightly as the temperature increased, which suggests that the temperature favoured the formation of a more porous film. Capacitance values increased in general with temperature, indicating a decrease in the passive layers thickness and worse behaviour of UB6 against corrosion.

(3) The Mott-Schottky plots have shown both p-type and n-type semiconducting behaviours. Calculated acceptor/donor densities of UB6 in the contaminated phosphoric acid revealed an increase of the acceptor/donor densities with the temperature, whose values are of the order of $10^{20} \mathrm{~cm}^{-3}$. According to the obtained results, it can be concluded that the passive film formed on UB6 steel has a disordered structure and becomes more defective at higher temperatures.

\section{References}

[1] P. Becker, Phosphates and Phosphoric Acid. Raw Materials, Technology, and Economics of the Wet Process, M. Dekker, New York, NY, USA, 2nd edition, 1989.

[2] A. Bellaouchou, A. Guenbour, and A. Benbachir, "Corrosion behavior of stainless steel in phosphoric acid polluted by sulfide ions," Corrosion, vol. 49, no. 8, pp. 656-662, 1993.

[3] S. El Hajjaji, L. Aries, J.-P. Audouard, and F. Dabosi, "The influence of alloying elements on the corrosion resistance of stainless steels in phosphoric acid medium polluted by sulphide ions," Corrosion Science, vol. 37, no. 6, pp. 927-939, 1995.

[4] H. Iken, R. Basseguy, A. Guenbour, and A. B. Bachir, "Classic and local analysis of corrosion behaviour of graphite and 
stainless steels in polluted phosphoric acid," Electrochimica Acta, vol. 52, no. 7, pp. 2580-2587, 2007.

[5] A. Guenbour, M. Hajji, E. M. Jallouli, and A. B. Bachir, "Study of corrosion-erosion behaviour of stainless alloys in industrial phosphoric acid medium," Applied Surface Science, vol. 253, no. 5, pp. 2362-2366, 2006.

[6] H. Streblow and P. Marcus, Corrosion Mechanisms in Theory and Practice, Marcel Dekker, New York, NY, USA, 1995.

[7] S. Rajeswari, K. S. Danadurai, T. M. Sridhar, and S. V. Narasimhan, "Surface characterization and pitting behavior of high-Cr-Ni-Mo alloys in simulated white water environment," Corrosion, vol. 57, no. 5, pp. 465-475, 2001.

[8] J. H. Qiu, "Passivity and its breakdown on stainless steels and alloys," Surface and Interface Analysis, vol. 33, no. 10-11, pp. 830833, 2002.

[9] G. C. Frenkel, "Pitting corrosion of metals: a review of the critical factors," Journal of the Electrochemical Society, vol. 145, pp. 2186-2198, 1998.

[10] M. A. Ameer, A. M. Fekry, and F. E. Heakal, "Electrochemical behaviour of passive films on molybdenum-containing austenitic stainless steels in aqueous solutions," Electrochimica Acta, vol. 50, no. 1, pp. 43-49, 2004.

[11] A. Galal, N. F. Atta, and M. H. S. Al-Hassan, "Effect of some thiophene derivatives on the electrochemical behavior of AISI 316 austenitic stainless steel in acidic solutions containing chloride ions: I. Molecular structure and inhibition efficiency relationship," Materials Chemistry and Physics, vol. 89, no. 1, pp. 38-48, 2005.

[12] S. A. M. Refaey, F. Taha, and A. M. A. El-Malak, "Corrosion and inhibition of stainless steel pitting corrosion in alkaline medium and the effect of $\mathrm{Cl}$ - and Br-anions," Applied Surface Science, vol. 242, no. 1-2, pp. 114-120, 2005.

[13] S. A. M. Refaey, "Inhibition of chloride pitting corrosion of mild steel by sodium gluconate," Applied Surface Science, vol. 157, pp. 199-206, 2000.

[14] S. S. Abd El-Rehim, S. A. M. Refaey, F. Taha, M. B. Saleh, and R. A. Ahmed, "Corrosion inhibition of mild steel in acidic medium using 2-amino thiophenol and 2-cyanomethyl benzothiazole," Journal of Applied Electrochemistry, vol. 31, no. 4, pp. 429-435, 2001.

[15] A. Fattah-Alhosseini, S. T. Shoja, B. H. Zebardast, and P. M. Samim, "An electrochemical impedance spectroscopic study of the passive state on AISI 304 stainless steel," International Journal of Electrochemistry, vol. 7, pp. 8-13, 2011.

[16] H. A. El Dahan, "Pitting corrosion inhibition of 316 stainless steel in phosphoric acid-chloride solutions, part I: potentiodynamic and potentiostatic polarization studies," Journal of Materials Science, vol. 34, no. 4, pp. 851-857, 1999.

[17] J. Lee, "Effects of alloying elements, Cr, Mo and $\mathrm{N}$ on repassivation characteristics of stainless steels using the abrading electrode technique," Materials Chemistry and Physics, vol. 99, no. 2-3, pp. 224-234, 2006.

[18] M. A. M. Ibrahim, S. S. Abd El Rehim, and M. M. Hamza, "Corrosion behavior of some austenitic stainless steels in chloride environments," Materials Chemistry and Physics, vol. 115, no. 1, pp. 80-85, 2009.

[19] A. Guenbour, S. Zeggaf, A. Ben Bachir, M. L. Escudero, and M. F. Lopez, "Effect of mineral compounds in phosphoric acid polluted by sulfide ions on corrosion of nickel," Corrosion, vol. 55, no. 6, pp. 576-581, 1999.
[20] A. Bellaouchou, A. Geunbour, and A. Benbachir, "The corrosion of an austenitic stainless steel in phosphoric acid: effect of sulphide ions action," Bulletin of Electrochemistry, vol. 16, pp. 166-172, 2000.

[21] A. Guenbour, N. Bui, I. Fauchcu, Y. Segui, A. Ben Bachir, and F. Dabosi, "The electrical properties of passive films formed on stainless steels in phosphoric acids," Corrosion Science, vol. 30, no. 2-3, pp. 189-199, 1990.

[22] A. Guenbour, H. Iken, N. Kebkab, A. Bellaouchou, R. Boulif, and A. B. Bachir, "Corrosion of graphite in industrial phosphoric acid," Applied Surface Science, vol. 252, no. 24, pp. 8710-8715, 2006.

[23] S. R. Moraes, D. Huerta-Vilca, and A. J. Motheo, "Corrosion protection of stainless steel by polyaniline electrosynthesized from phosphate buffer solutions," Progress in Organic Coatings, vol. 48, no. 1, pp. 28-33, 2003.

[24] M. Abdellah, "Corrosion behaviour of 304 stainless steel in sulphuric acid solutions and its inhibition by some substituted pyrazolones," Materials Chemistry and Physics, vol. 82, no. 3, pp. 786-792, 2003.

[25] L. Wegrelius, F. Falkenberg, and I. Olefjord, "Passivation of stainless steels in hydrochloric acid," Journal of the Electrochemical Society, vol. 146, no. 4, pp. 1397-1406, 1999.

[26] M. Reffass, R. Sabot, M. Jeannin, C. Berziou, and P. Refait, "Effects of phosphate species on localised corrosion of steel in $\mathrm{NaHCO}_{3}+\mathrm{NaCl}$ electrolytes," Electrochimica Acta, vol. 54, no. 18, pp. 4389-4396, 2009.

[27] E. Almeida, D. Pereira, M. O. Figueiredo, V. M. M. Lobo, and M. Morcillo, "The influence of the interfacial conditions on rust conversion by phosphoric acid," Corrosion Science, vol. 39, no. 9, pp. 1561-1570, 1997.

[28] A. Guenbour, J. Faucheu, A. Ben Bachir, F. Dabosi, and N. Bui, "Electrochemical study of corrosion-abrasion of stainless steels in phosphoric acids," British Corrosion Journal, vol. 23, no. 4, pp. 234-238, 1988.

[29] A. M. P. Simões, M. G. S. Ferreira, G. Lorang, and M. D. Belo, "Influence of temperature on the properties of passive films formed on AISI 304 stainless steel," Electrochimica Acta, vol. 36, pp. 315-320, 1991.

[30] E. Sikora and D. D. Macdonald, "Nature of the passive film on nickel," Electrochimica Acta, vol. 48, no. 1, pp. 69-77, 2002.

[31] N. Sato and K. Kudo, "An ellipsometric study of anodic passivation of nickel in borate buffer solution," Electrochimica Acta, vol. 19, no. 8, pp. 461-470, 1974.

[32] N. B. Hakiki, S. Boudin, B. Rondot, and M. D. Belo, "The electronic structure of passive films formed on stainless steels," Corrosion Science, vol. 37, no. 11, pp. 1809-1822, 1995.

[33] J. Pan, C. Leygraf, R. F. A. Jargelius-Pettersson, and J. Lindén, "Characterization of high-temperature oxide films on stainless steels by electrochemical-impedance spectroscopy," Oxidation of Metals, vol. 50, no. 5-6, pp. 431-455, 1998.

[34] M. Belo, N. E. Hakiki, and M. G. S. Ferreira, "Semiconducting properties of passive films formed on nickel-base alloys type Alloy 600: influence of the alloying elements," Electrochimica Acta, vol. 44, no. 14, pp. 2473-2481, 1999.

[35] M. F. Montemor, M. G. S. Ferreira, N. E. Hakiki, and M. Belo, "Chemical composition and electronic structure of the oxide films formed on 316L stainless steel and nickel based alloys in high temperature aqueous environments," Corrosion Science, vol. 42, no. 9, pp. 1635-1650, 2000. 
[36] M. G. S. Ferreira, N. E. Hakiki, G. Goodlet, S. Faty, A. M. P. Simoes, and M. D. Belo, "Influence of the temperature of film formation on the electronic structure of oxide films formed on 304 stainless steel," Electrochimica Acta, vol. 46, pp. 3767-3776, 2001.

[37] H. Ge, G. Zhou, and W. Wu, "Passivation model of 316 stainless steel in simulated cooling water and the effect of sulfide on the passive film," Applied Surface Science, vol. 211, no. 1-4, pp. 321334, 2003.

[38] G. Rondelli, P. Torricelli, M. Fini, and R. Giardino, "In vitro corrosion study by EIS of a nickel-free stainless steel for orthopaedic applications," Biomaterials, vol. 26, no. 7, pp. 739$744,2005$.

[39] M. J. Carmezim, A. M. Simões, M. F. Montemor, and M. Belo, "Capacitance behaviour of passive films on ferritic and austenitic stainless steel," Corrosion Science, vol. 47, no. 3, pp. 581-591, 2005.

[40] J. Pan, D. Thierry, and C. Leygraf, "Electrochemical impedance spectroscopy study of the passive oxide film on titanium for implant application," Electrochimica Acta, vol. 41, no. 7-8, pp. 1143-1153, 1996.

[41] F. Mansfeld and M. W. Kendig, "Evaluation of anodized aluminum surfaces with electrochemical impedance spectroscopy," Journal of the Electrochemical Society, vol. 135, no. 4, pp. 828-833, 1988.

[42] A. Igual-Munoz, J. Garcia-Anton, J. L. Guinon, and V. PerezHerranz, "Inhibition effect of chromate on the passivation and pitting corrosion of a duplex stainless steel in LiBr solutions using electrochemical techniques," Corrosion Science, vol. 49, no. 8, pp. 3200-3225, 2007.

[43] P. Bommersbach, C. Alemany-Dumont, J. P. Millet, and B. Normand, "Formation and behaviour study of an environmentfriendly corrosion inhibitor by electrochemical methods," Electrochimica Acta, vol. 51, no. 6, pp. 1076-1084, 2005.

[44] M. E. Orazem and B. Tribollet, Electrochemical Impedance Spectroscopy, chapter 13, John Wiley and Sons, Hoboken, NJ, USA, 1st edition, 2008.

[45] C. V. Vidal and A. I. Muñoz, "Study of the adsorption process of bovine serum albumin on passivated surfaces of CoCrMo biomedical alloy," Electrochimica Acta, vol. 55, no. 28, pp. 84458452, 2010.

[46] N. P. Cosman, K. Fatih, and S. G. Roscoe, "Electrochemical impedance spectroscopy study of the adsorption behaviour of $\alpha$-lactalbumin and $\beta$-casein at stainless steel," Journal of Electroanalytical Chemistry, vol. 574, no. 2, pp. 261-271, 2005.

[47] A. Kocijan, D. K. Merl, and M. Jenko, “The corrosion behaviour of austenitic and duplex stainless steels in artificial saliva with the addition of fluoride," Corrosion Science, vol. 53, no. 2, pp. 776-783, 2011.

[48] D. D. Macdonald, A. Sun, N. Priyantha, and P. Jayaweera, "An electrochemical impedance study of Alloy-22 in $\mathrm{NaCl}$ brine at elevated temperature: II. Reaction mechanism analysis," Journal of Electroanalytical Chemistry, vol. 572, no. 2, pp. 421-431, 2004.

[49] D. Macdonald and M. C. H. McKubre, Impedance Spectroscopy: Theory, Experiment, and Applications, E. Barsoukov, J. R. Macdonald, Eds., chapter 4, John Wiley and Sons, Hoboken, NJ, USA, 2nd edition, 2005.

[50] T. L. S. L. Wijesinghe and D. J. Blackwood, "Photocurrent and capacitance investigations into the nature of the passive films on austenitic stainless steels," Corrosion Science, vol. 50, no. 1, pp. 23-34, 2008.
[51] D. Wallinder, J. Pan, C. Leygraf, and A. Delblanc-Bauer, "EIS and XPS study of surface modification of 316LVM stainless steel after passivation," Corrosion Science, vol. 41, no. 2, pp. 275-289, 1999.

[52] Y. X. Qiao, Y. G. Zheng, W. Ke, and P. C. Okafor, "Electrochemical behaviour of high nitrogen stainless steel in acidic solutions," Corrosion Science, vol. 51, no. 5, pp. 979-986, 2009.

[53] G. Blanco, A. Bautista, and H. Takenouti, "EIS study of passivation of austenitic and duplex stainless steels reinforcements in simulated pore solutions," Cement and Concrete Composites, vol. 28, no. 3, pp. 212-219, 2006.

[54] M. Bojinov, G. Fabricius, P. Kinnunen et al., "Electrochemical study of the passive behaviour of $\mathrm{Ni}-\mathrm{Cr}$ alloys in a borate solution-a mixed-conduction model approach," Journal of Electroanalytical Chemistry, vol. 504, pp. 29-44, 2001.

[55] R. M. Fernández-Domene, E. Blasco-Tamarit, D. M. GarcíaGarcía, and J. García-Antón, "Thermogalvanic corrosion of Alloy 31 in different heavy brine $\mathrm{LiBr}$ solutions," Corrosion Science, vol. 55, pp. 40-53, 2012.

[56] C.-O. A. Olsson and D. Landolt, "Passive films on stainless steels-chemistry, structure and growth," Electrochimica Acta, vol. 48, no. 9, pp. 1093-1104, 2003.

[57] M. H. Dean and U. Stimming, "The electronic properties of disordered passive films," Corrosion Science, vol. 29, no. 2-3, pp. 199-211, 1989.

[58] B. G. Craig, Ed., Fundamental Aspects of Corrosion Films on Corrosion Science, vol. 58, Plenum Press, New York, NY, USA, 1991.

[59] R. Babić and M. Metikoš-Huković, "Semiconducting properties of passive films on AISI 304 and 316 stainless steels," Journal of Electroanalytical Chemistry, vol. 358, no. 1-2, pp. 143-160, 1993.

[60] D. D. MacDonald, "On the existence of our metals-based civilization I. Phase-space analysis," Journal of the Electrochemical Society, vol. 153, no. 7, pp. B213-B224, 2006.

[61] C. Sunseri, S. Piazza, and F. di Quarto, "Photocurrent spectroscopic investigations of passive films on chromium," Journal of the Electrochemical Society, vol. 137, no. 8, pp. 2411-2417, 1990.

[62] X. Cheng, X. Li, and C. Du, "Properties of passive film formed on 316L/2205 stainless steel by Mott-Schottky theory and constant current polarization method," Chinese Science Bulletin, vol. 54, no. 13, pp. 2239-2246, 2009.

[63] D. D. Macdonald, "Point defect model for the passive state," Journal of the Electrochemical Society, vol. 139, no. 12, pp. 34343449, 1992.

[64] G. Lothongkum, S. Chaikittisilp, and A. W. Lothongkum, "XPS investigation of surface films on high $\mathrm{Cr}-\mathrm{Ni}$ ferritic and austenitic stainless steels," Applied Surface Science, vol. 218, no. 1-4, pp. 203-209, 2003.

[65] H. Habazaki, A. Kawashima, K. Asami, and K. Hashimoto, "The corrosion behavior of amorphous Fe-Cr-Mo-P-C and Fe-Cr-W$\mathrm{P}-\mathrm{C}$ alloys in $6 \mathrm{M} \mathrm{HCl}$ solution," Corrosion Science, vol. 33, no. 2, pp. 225-236, 1992.

[66] M.-W. Tan, E. Akiyama, A. Kawashima, K. Asami, and K. Hashimoto, "The effect of air exposure on the corrosion behavior of amorphous Fe-8Cr-Mo-13P-7C alloys in $1 \mathrm{M} \mathrm{HCl,"}$ Corrosion Science, vol. 37, no. 8, pp. 1289-1301, 1995.

[67] S. R. Morrison, Electrochemistry at Semiconductor and Oxidised Metal Electrodes, Plenum Press, New York, NY, USA, 1980.

[68] N. Sato, Electrochemistry at Metal and Semiconductor Electrodes, Elsevier Science, Amsterdam, The Netherland, 1st edition, 1998. 
[69] E. Cho, H. Kwon, and D. D. Macdonald, "Photoelectrochemical analysis on the passive film formed on $\mathrm{Fe}-20 \mathrm{Cr}$ in $\mathrm{pH} 8.5$ buffer solution," Electrochimica Acta, vol. 47, pp. 1661-1668, 2002.

[70] M. Metikos-Hukovic, R. Babic, Z. Grubac, Z. Petrovic, and N. Lajci, "High corrosion resistance of austenitic stainless steel alloyed with nitrogen in an acid solution," Corrosion Science, vol. 53, no. 6, pp. 2176-2183, 2011.

[71] M. G. S. Ferreira and J. L. Dawson, "Electrochemical studies of the passive film on 316 stainless steel in chloride media," Journal of The Electrochemical Society, vol. 4, pp. 760-765, 1985.

[72] H. Jang and H. Kwon, "In situ study on the effects of $\mathrm{Ni}$ and Mo on the passive film formed on $\mathrm{Fe}-20 \mathrm{Cr}$ alloys by photoelectrochemical and Mott-Schottky techniques," Journal of Electroanalytical Chemistry, vol. 590, pp. 120-125, 2006. 

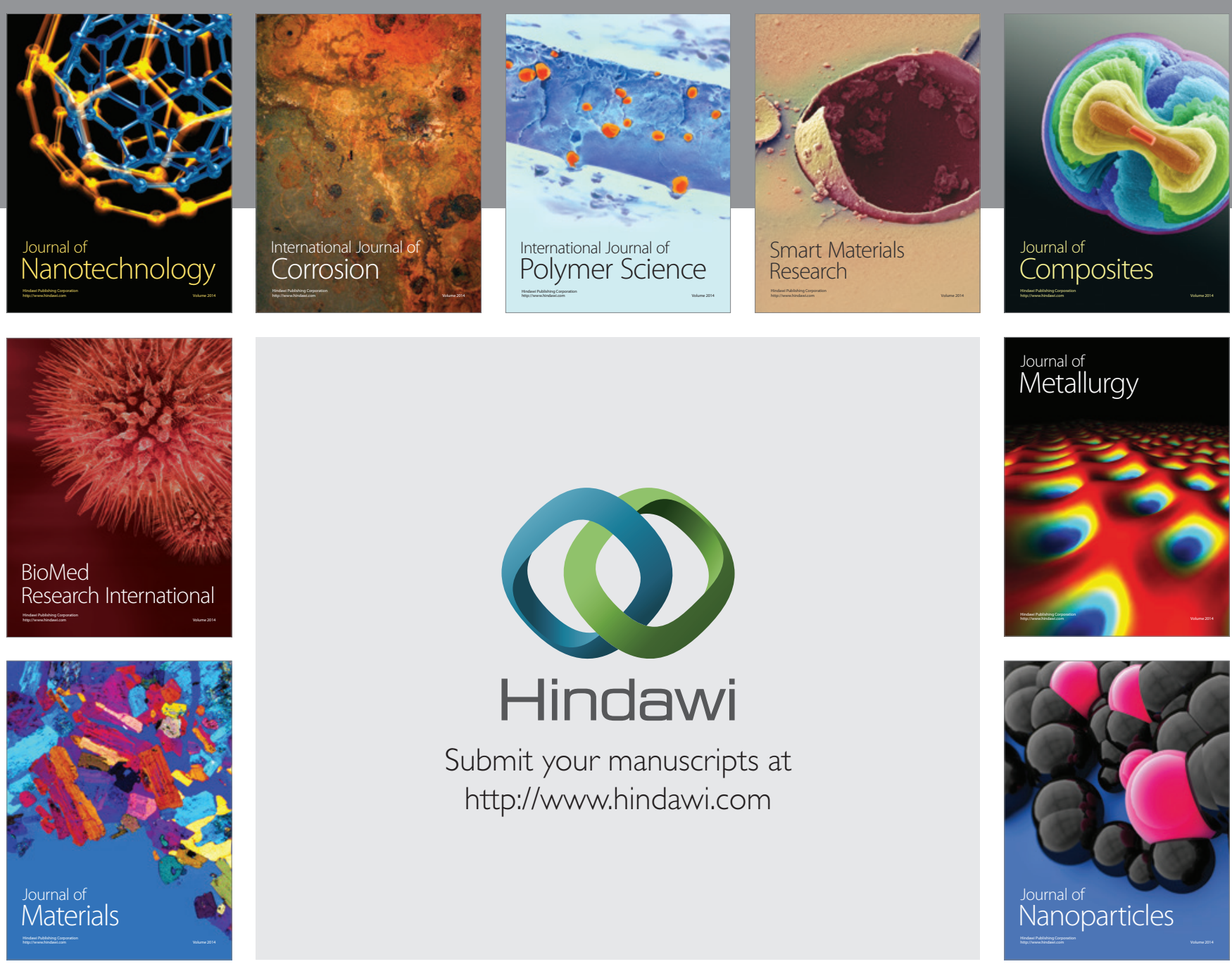

Submit your manuscripts at http://www.hindawi.com
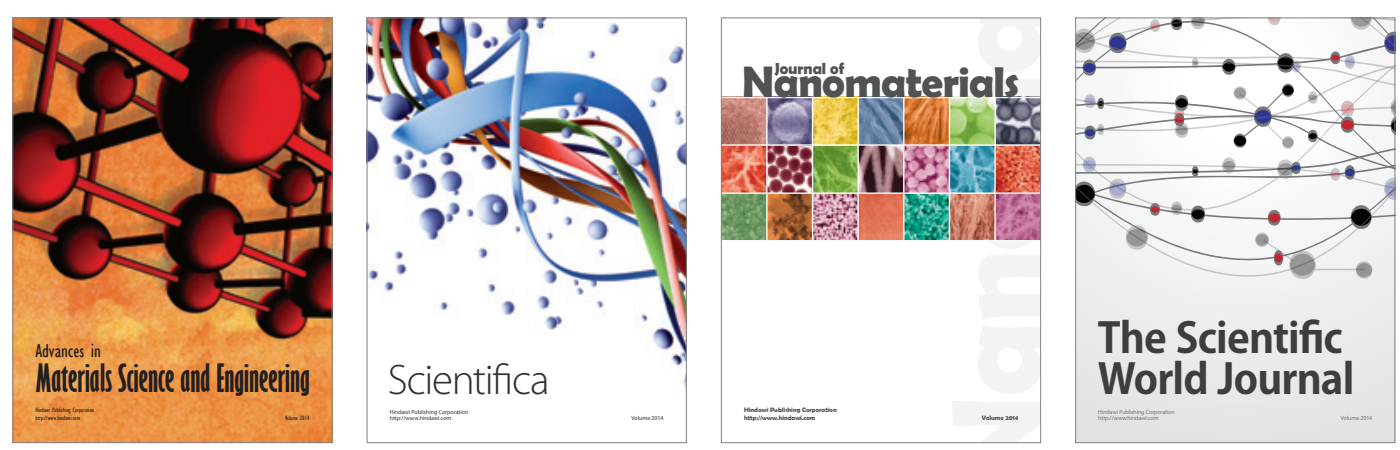

\section{The Scientific World Journal}
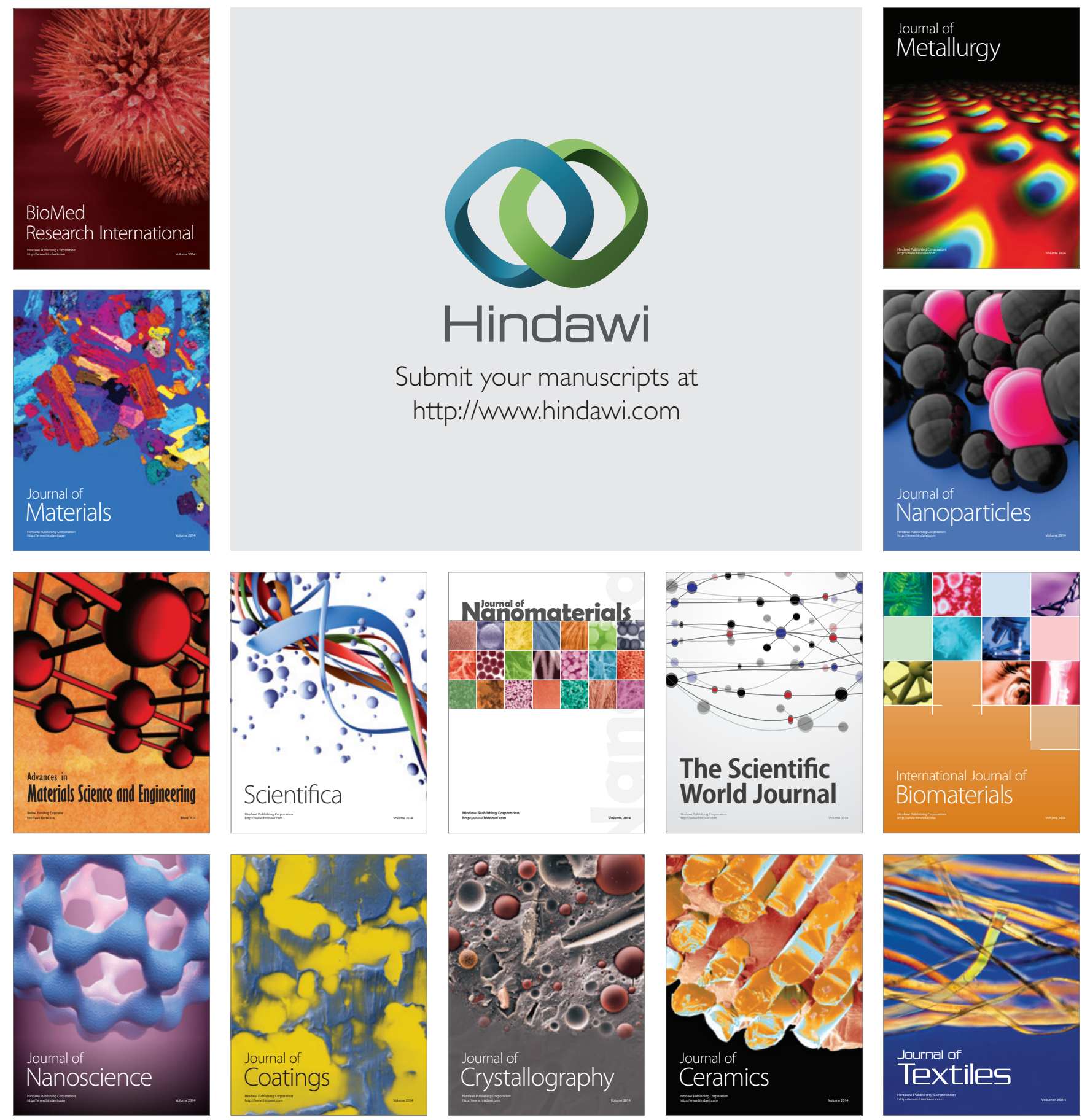